\title{
DESAFIO LATINO AMERICANO: CONSOLIDAÇÃO DE UM IDEAL DEMOCRÁTICO
}

\section{LATIN AMERICAN CHALLENGE: CONSOLIDATION OF A DEMOCRATIC IDEAL}

\author{
${ }^{1}$ Dostoievsky Ernesto De Melo Andrade \\ ${ }^{2}$ Carla Danielle Barreto de Sousa Sabino
}

\section{RESUMO}

A qualidade da democracia é analisada pela capacidade de alavancar o potencial de várias dimensões que caracterizam os mecanismos que controlam o exercício do poder político. $\mathrm{Na}$ América Latina o modo particular de relação entre estado e cidadãos está fragilizada pelo contexto social, econômico e político. Com efeito, na América Latina, um dos problemas de qualidade democrática é a debilidade destes mecanismos de controle e de como as consequências deste modelo repercute na cultura transgressora. Firmar uma estrutura de estado que estabeleça coesão social através da participação cidadã é uma dos grandes desafios a serem alcançados pela América Latina.

Palavras-chave: Democracia, Qualidade, América latina

\begin{abstract}
The quality of democracy is analyzed by the ability to leverage the potential of various dimensions that characterize the mechanisms that control the exercise of political power. In Latin America the particular mode of relationship between state and citizens is weakened by social, economic and political context. Indeed, in Latin America, one of the democratic quality problems is the weakness of these control mechanisms and the consequences of this model affects the transgressive culture. Establish a state structure to establish social cohesion through citizen participation is one of the major challenges to be met by Latin America.
\end{abstract}

Keywords: Democracy, Quality, Latin america

\footnotetext{
${ }^{1}$ Mestrando pelo Centro Universitário de João Pessoa, Paraíba (Brasil) E-mail: dosto11@ @otmail.com

${ }^{2}$ Mestranda pelo Centro Universitário de João Pessoa, Paraíba (Brasil) E-mail: carladaniellebss@gmail.com
} 


\section{INTRODUÇÃO}

Analisar o contexto de direitos e participação política na América Latina está direcionado a alcançar condições que permitam o acesso a participação às instituições políticas formais. Aprofundar a reflexão sobre a sociedade latina e a representação, continua sendo um grande desafio. A análise da democracia e de sua qualidade perpassa pela apreciação crítica de suas dimensões e de como no âmbito político a estrutura do sistema declina para formas especiais de regime que deteriora a democracia a exemplo do neopopulismo.

Em seu contexto histórico a América Latina passa por décadas de debilidade em seus processos políticos ancorados no regime democrático. As instituições e os processo políticos que operam dentro das restrições moldadas pelos regimes híbridos adotados viabilizam formas particulares de processo político. É preciso conceber inovações e reformas que possam moldar a forma como as forças sociais e a sociedade civil devam assumir com mais concretude as tarefas da política.

Sabe-se que para estabelecer uma democracia sob o regime exato de qualidade deve-se observar sufrágio universal; eleições livres, competitivas e recorrentes, existência de competição entre mais de um partido político além de fontes alternativas de informação. São estes procedimentos que garantem conciliar liberdade e igualdade política, pilares da democracia.

A representação política expressa a clara ideia liberal de democracia, mas não pode ser considerada como elemento vital dentre as demais dimensões da qualidade. Uma democracia de qualidade deve prover a seus cidadãos um alto grau de liberdade, igualdade política e controle popular sobre os tomadores de decisão e as políticas públicas, através do funcionamento pleno e conciliado com os interesse coletivos e operados em instituições estáveis.

As grandes dificuldades de implementação desta coesão não se restringe apenas ao campo político, a expansão da transgressão e violência na América Latina, fruto da desigualdade latente, são fatores expressivos do grave problema que altera o contexto político destes países. O fenômeno da corrupção é um das dimensões mais lesivas à democracia e afeta inúmeros domínios da vida social e fomenta os regimes autoritários e o populismo. 
Como a democracia implica em autonomia e emancipação social, nesta perspectiva, participar ativamente nas decisões políticas promoverá impacto direto na esfera econômica, política, social e cultural. A participação deve ampliar o acesso em variados segmentos da vida cidadã. Na América Latina, diante da frágil situação político-econômica, o obstáculo à cidadania impede que uma afirmação cultural democrática se instale.

Desta forma, o objetivo deste estudo é apresentar os marcadores que garantem a qualidade que legitimam a democracia na América Latina assim como pretende dissecar as dimensões que debilita a condição política destes países com impacto no campo econômico, social e cultural. A metodologia aplicada neste estudo é de caráter descritivo, exploratório, bibliográfico e utilizando o método dedutivo-hipotético.

\section{QUALIDADE E LEGIMITADE DA DEMOCRACIA NA AMÉRICA LATINA}

No final do século XVIII a inviabilidade consternada na democracia participativa não conciliava com os projetos de poder da moderna sociedade burguesa, e assim, o sistema representativo ganhava força nos debates a ponto de materializar-se como sistema político que consolidou a lógica política de organização. Daí o avanço para uma democracia representativa.

A democracia é uma forma de relação social e política que permite que os membros de uma sociedade tenha acesso a bens materiais e culturais por ela geradas, estabelecidas por tomadas de decisão em relação a esses produtos sociais. É considerado um sistema de emancipação social assentada em uma base de sustentação sob o princípio da igualdade social. Portanto, as liberdades individuais e públicas são uma condição essencial para que uma sociedade democrática possa decidir sobre o destino político de forma independente. O requisito da igualdade social é uma condição necessária para a democracia que se materializa com a realização das liberdades individuais. É manifesto que uma sociedade desigual, como é a da América Latina, verificar-se que a desproporcional relação entre a capacidade de tomada de decisão, concentrada em uma minoria em face de uma maioria, exerce liberdades limitadas por mecanismos institucionais que violam estes princípios fundamentais.

A democracia pode ser utilizada como instrumento de regulação política em uma cenário de produção capitalista. Diante da concepção conservadora do liberalismo a democracia consagra-se como ferramenta instrumental do modelo de 
produção. Neste período em que a gênese se conforma com as pretensões da burguesia, o voto censitário assume como estratégia de conservação do poder oligárquico. Como resultados das lutas sociais em massa, o sufrágio universal torna- se institucionalizado forçando assim fortalecer os mecanismo de controle político. Por conseguinte, em uma sociedade desigual tal modelo é indispensável para sobrevivência da democracia afim de combater um conjunto de interesses com substrato capitalista e político de pretensões para domínio do poder hegemônico.

As ideias liberais estabelecem uma relação com o Estado em uma perspectiva limitada de intervenção, cuja ordem política vai se delineando para atender principalmente aos interesses da classe individualista e assim favorecer a expansão do poder econômico e do mercado. Durante o transcurso da história, os problemas envolvendo a democracia obstinada em excluir certas dimensões do campo social, padeceu de forma crônica com exclusão de mulheres ao voto e restrição da noção de democracia ao voto, limitando consideravelmente os espaços de construção democrática e identificando domínios da liberdade individual com a liberdade de mercado, reflexo do sistema de economia capitalista.

A democracia é um sistema de representação com participação livre e universal. Marcado por igualdade de direitos e que os cidadãos são submetidos á regras semelhantes, podendo influenciar nas decisões políticas e exigir, por sua vez, a responsabilidade dos governantes. É importante destacar que o sistema competitivo de eleições não pode configurar-se como elemento vital para estabelecer qualidade de democracia, visto que outras dimensões assumem importância relevante e indispensável para o sistema político. Para Levine (2006, p. 22), há um amplo reconhecimento de que os procedimentos e significativo trabalho de manutenção da democracia processual deva considerar alguns requisitos mínimos: cidadania inclusiva tão abertos, acessíveis e claras e relativamente igualdade de condições na atividade política a indivíduos e organizações, liberdade de informação e organização, e mecanismos formais e informais para garantir a prestação de contas e a responsabilidade da classe governante.

Na concepção de Atíltio Boron (2009, p. 20-23) o governo de natureza democrática e de maioria está a serviço dos mais carentes, no entanto, a aparência de amparo não corresponde a essência destas pretensões de arrimo para com a sociedade, pois as formalidades aparentes de democracia divorcia-se de seu conteúdo e convertese em um regime que não o é. Contribui para este estado, a forma como o sistema 
capitalista vem inserindo em sua máquina operacional a conversão de várias dimensões da vida social em mercado. Com efeito, isto também invade instituições do estado, vulneráveis aos interesses do mercado gerenciados pela elite econômica que influenciam decisões políticas para atender a interesses específicos de não proveito para a coletividade.

As deliberações políticas subsidiadas pelos interesses de uma elite dominante postos a serviços do mercado, exclui milhões de pessoas apesar de estarem envolvidos em processos institucionais que se conformam com a essência da democracia, a exemplo do direito ao voto (que mantém ainda uma condição mínima de participação). No entanto, esta condição de privação nas tomadas de decisão que atendam aos interesses da maioria vem contribuindo para o avanço da miséria que são sintomas característicos da economia de mercado.

A crise da democracia está cada vez mais exclusiva e vem se instalando na América Latina diante de outros componentes que estão se deteriorando a exemplo das relações sociais, violência, miséria e fragilidade econômica. Para Dussel (2007, p. 184) a crise de representatividade política considera a negação de direitos e manipulação de consensos, porém, o poder do povo ainda se mostra forte o suficiente para não ser aniquilado mas tão somente enfraquecido. Para debilitar o poder do povo é necessário destruir seus consensos, que no âmbito coletivo, não se configura pois aduz a muitos contextos nem sempre conciliados. Portanto, é na reivindicação de direitos apresentados pelos agrupamentos sociais, especialmente na forma de movimentos populares, que emergem a possiblidade de ampliação da democracia para além das aparência, mas também pela essência.

Com a crise do capitalismo nos anos setenta o liberalismo conservador adotado na América Latina tem por ambição exercer controle social e político sobre as massas afim de garantir sua subordinação e manter uma boa parte da população excluída da tomada de decisão. As pretensões de estruturar novos mecanismos de dominação muitas vezes operadas as margens da legitimidade, desequilibra os modelos democráticos das instituições e fragmenta a população em um conjunto de interesses que não se conciliam, e que, convergidas em forças opostas não formam consensos indispensáveis para o desenvolvimento de uma ação coletiva que beneficie a todos.

As mudanças democráticas que se lançam nos discursos para assegurar os princípios da igualdade, em uma base de equilíbrio do poder político, obedece a uma 
estruturação de poder do estado que encontra-se inserido em uma plataforma de ações e projetos que não se inclinam as tendências elitistas e que força o estado a atender a seus interesses capitalistas. A abertura à participação popular é sempre um mecanismo complexo nos países da América Latina, pois as desiguais manifestações da prática democrática comprometeu a consolidação dos ideais democráticos.

É a partir da industrialização, urbanização e o crescente desenvolvimento dos setores médios urbanos que os partidos políticos modernos de natureza populista cresce sob o contexto do discurso democrático. A expressão de ilustrar a soberania popular em um cenário de igualdade política, justiça social, nacionalismo, antiimperialismo e antioligarquismo são elementos essenciais dos projetos populistas para obter adesão da comunidade mais carente do amparo do Estado. O discurso estruturado nestes domínios convergido na figura de uma liderança personalista estabelece um contato quase místico com as massas. (MORALES E EMÉNDEZ, 2005).

O populismo é marcado pela ideologia da redistribuição de riquezas e este motivo de grande relevância e de impacto social muitas vezes justifica as práticas ilegais para garantir a lealdade política conciliada aos interesses da coletividade. Neste aspecto, Romero (1996) expressa como uma das principais características do populismo:

O Estado de Direito não é um valor político significativo no quadro ideológico populista o mais importante é o compromisso com o movimento ou partido e a obediência ao líder carismático. As massas são fundamentais e a partir de uma perspectiva econômica o populismo reforça o papel do Estado na vida econômica, profundamente desconfiada do mercado sendo retoricamente anticapitalista (Romero, 1996: 374).

É certo que a influência das desigualdades econômicas ecoando no cerne das questões políticas transformam diretamente os traços e a práxis da tradicional política. A polarização gerada pela disparidade social e econômica do grupo vulnerável à exploração e aos efeitos da política dominante, cria um potencial gerador de conflitos entre classes. O cenário é de descrédito do governo e das instituições políticas, por não conseguir contemplar as demandas sociais como uma prioridade, deixando livre à conveniência do ideal populista, revestido de apelos demagógicos resultado da fragilidade do setor popular que não mais atribui qualquer crédito às instituições do Estado.

Como o desenvolvimento do capitalismo, cujo predomínio da produção se concentrou no consumo; substituição de importações e distribuição progressiva de 
renda, um discurso ideológico estruturado na figura do líder, consolidou a lealdade popular impulsionado ainda mais por políticas de redistribuição de renda que fomenta o consumismo e otimiza o mercado interno, garantindo a rentabilidade do capital privado. O populismo é caracterizado como um movimento político que se desenvolve em resposta às crises do desenvolvimento e que envolve múltiplas dimensões: histórica, sociológica, econômica, ideológica e política. Neste último campo, o neopopulismo rejeita a atividade legislativa e lança mão de medidas provisórias e decretos-leis para governar e tomar decisões que beiram à excentricidade.

O populismo assinala em sua essência um caráter mais manipulativo através de uma confluência de ações clientelistas por meio de políticas públicas de cunho assistencialista, cuja pretensão política é obter apoio dos chamados setores subalternos e das classes populares excluídas dos programas de assistência dos governos liberais. $\mathrm{O}$ engessamento das classes sociais na América Latina, contribuiu para o surgimento dos movimento populistas marcados pela contingente condição estrutural da ordem econômica e social, que viu-se nos líderes populistas a personificação messiânica para atender inúmeras demandas sociais básicas.

Para Perez-Liñan (2007) uma nova forma de instabilidade política se instala na América Latina a partir dos anos 90 sem necessariamente afetar o regime democrático, que se fragiliza e torna-se instável. Um período de grande turbulência que resultou em quedas de governo e profundas mudanças na ordem democrática, gerando a crise de legitimidade do regime democrático principalmente pela falta de apoio especifico de alguns setores políticos e do frágil funcionamento político do país. $\mathrm{O}$ descontentamento com o funcionamento do sistema resulta em corrosão de formas específicas de legitimidade democrática. Verifica-se que a ausência de apoio aos atores do regime, desempenho débil da economia e frágil funcionamento das instituições democráticas são motores para o acirramento da crise política que assolam a América Latina. Para Mainwaring (2006, p. 14) a queda de confiança nas instituições básicas da democracia, partidos políticos e poder legislativo e a insatisfação generalizada com a qualidade da democracia, estão na base das sucessivas crises da democracia movida principalmente pela crise de representação. Para o supracitado autor os mecanismos tradicionais de intermediação de interesses em democracias representativas são extremamente frágeis na América Latina e são suplantados por relações clientelistas e personalistas entre eleitos e eleitores. 
A crise dos partidos permitiu que partidos tradicionais perdessem credibilidade. A ausência de contato de setores da população com as instituições políticas clássicas são um sinal de falência dos partidos políticos e do poder legislativo que não conseguem suprir a disposição de serviços básicos de boa qualidade gerando desequilíbrio econômico e social, motivados pela má gestão e corrupção dos funcionários públicos que devasta a confiança nas instituições. Esta queda de apoio institucional é fruto da baixa qualidade produzida pelos sistemas políticos cuja a qualidade repercute diretamente nas instituições democráticas e condicional a sua legitimidade. Regimes ineficientes no combate a pobreza, incremento da desigualdade, corrupção disseminada e pouco investimento nas estratégias para redução da criminalidade deterioram a adesão representativa no campo político.

O apoio difuso e específico da população ao regime democrático tem relação direta com a sobrevivência do próprio regime. No entanto, o que se observa na América Latina é a corrosão do regime mesmo mantendo-se ativo sem ruptura absoluta de sua regência com o funcionamento das instituições democráticas. A queda do apoio ao regime se mostra mas declinado a descrença destas instituições que não mais impera sobre o ditames da essência de sua expressão com que se define, sendo portanto, um indicador absoluto da queda da qualidade da democracia.

Mesmo em experiências autoritárias, não há rupturas diretas ao regime democrático, com eleições ocorrendo periodicamente, embora maculadas pela manipulação e fraudes e muitas vezes com alternância do poder e até competição entre partidos políticos

As reformas adotadas pelo Estado como estabilização monetária, interferência do Estado e certos mecanismos da política, economia e adoção de programas sociais norteados por critérios de eficiência, focalizaram os setores mais pobres da população. Por outro lado, o modelo estatizante de nacionalismo arraigado com o Estado assumindo o protagonismo no setor econômico, mobilizando apoio popular com política assistencialista, asfixiou o estado que empreendeu no regime autoritário uma forma de sedimentar-se no poder.

Para Sorj (2008, p.265) carências do regime tecnocrata reduzindo o papel do agente político a elaboração de políticas públicas; abandono na mão do mercado os problemas relativos ao emprego e a concepção que a sociedade esta reduzida em categorias para distribuição de rendas e que exige políticas sociais compensatórias, 
avoca uma reflexão que venha possibilitar mudanças paradigmáticas no cenário político. O supracitado autor defende a importância de estimular a busca por valores e crenças comuns, a partir da consolidação da democracia e da coesão social. Necessidade de encontrar valores comuns em que o povo possa identificar-se com os projetos do estado inserindo sua participação sob os pilares dos mecanismos democráticos no processo de globalização.

Os problemas relacionados à América Latina estão concentrados na impossibilidade de garantir o bem estar social compreendidos na sociedade de consumo, estão, por sua vez, vulneráveis às tentações populistas. O grande desafio é construir o arcabouço de um projeto que venha garantir ampla expressão individual a ser outorgada pelo Estado.

Mesmo com a queda da legitimidade política das democracias, a continuidade do regime não afasta as crises e ameaças iminentes de transformações profundas com quedas até de presidentes sem ruptura do regime. A estabilidade institucional baseada nos segmentos democráticos na América Latina ainda é um horizonte distante, pois a deterioração das bases de legitimidade vem acompanhada de crises institucionais de representação, quedas de governo, impasses constitucionais e eleitorais e de propostas radicais de alteração constitucional na direção de uma democracia iliberal (MAINWARING et al 2006).

A sociedade democrática operada sob os mecanismos de representação, na América Latina pode ser expressa em referendos, conselhos e orçamentos participativos e eleições. Contudo, as expectativas de uma sociedade mais participativa com representação mais autentica e de melhor qualidade não se manifesta em resposta à vontade coletiva e restrições ao acesso dos cidadãos e as inadequações entre as relações de grupos da sociedade civil e indivíduos e as instituições políticas e seus dirigentes. A qualidade e autenticidade da representação inclui estabelecer uma relação legítima com eleições justas, livres e frequentes e a forma como os representantes assumem suas responsabilidades. Para transformar este cenário faz-se necessário criar novos espaços urbanos, grupos sociais e estruturas institucionais do sistema político afim de constituir uma rede de representação (AVRITZER, 2002 p. 44)

Observa-se que o apoio ao regime democrático, um dos pilares de sustentação do sistema para que se consolide no meio social, converge em questões relacionadas a cultura, fruto da socialização experimentada pelo cidadão e ideologia, e pela performance do próprio regime político decorrentes do desempenho dos atores e 
instituições democráticas. Dahl (apud LEVINE e MOLINA, 2007 p. 22) considera a democracia um sistema em que cidadãos escolhem líderes e influenciam nas decisões. No entanto, para estabelecer uma relação de significação da própria noção de democracia é necessário que o governo represente os eleitos; que as eleições sejam livres, justas e frequentes; que haja liberdade de expressão; que os cidadãos tenham livre acesso as fontes alternativas de informação; liberdade de organização e reunião e cidadania inclusiva. Nesta perspectiva a qualidade da democracia deve perpassar por todos estes domínios em uma escala que pode se configurar para o cumprimento das condições mínimas aceitáveis no âmbito das decisão eleitoral até o processo de adoção de políticas e mecanismos públicos de exigência da responsabilidade dos governantes.

Nota-se que a ideologia democrática são analisadas sob um olhar mais crítico para aqueles com nível educacional mais alto e com mais informação política. Percebe-se que estes setores da população são mais integrados a comunidade política e conseguem valorizar e lutar pelos ideais democráticos básicos lutando pela integridade dos institutos a partir da censura ao desempenho precário de atores políticos e desempenho das instituições. Para Booth e Selingson (2006) as classes mais carentes rejeitam o regime por estarem inseridos em um contexto de corrupção e violência que os tornam vulneráveis às pretensões populistas.

Com a crise de representação do sistema político e com a perda da confiança pública nos atores políticos tradicionais, predispõe ao surgimento dos líderes, pela incompatibilidade de uma sociedade se alinhar a uma condução organizada. A crise dos mecanismos institucionais de representação são justamente recompostos pelo aparecimento de líderes (VILAS, 1995, p. 35). O discurso conciliado com a causa do povo dá ensejo a voz que preenche as esperanças. O líder trabalha por uma causa pessoal mas deforma a soberania do estado democrático por inferir demagogia no discurso, trazendo a figura do sagrado a um estado de reverência por tratar-se de um salvador dos males do capitalismo e da burguesia (TAGUIEFF, 2007, p. 10-11). A possibilidade de utilizar dos recursos do orçamento estatal, retórica que satisfaz a fé e confiança em uma possibilidade de estar vivendo o sentimento de pertencimento, além do contato direto com as massas, tem geralmente o objetivo de subordinar e condicionar o povo, e assim montar um exército de súditos e apoio político ilimitado. Com tanto poder, concentra-o para manejar qualquer possibilidade de insurgência, mesmo diante do mais incomum dos atos e decisões que afetam diretamente a 
economia a ordem social e institucional (GUERREIRO, OLIVA, 2007, p.7)

É certo que a participação política, condição levantada pelo discurso populista, é uma mera falácia e boa parte do apoio à ideologia neopopulista, dar-se-á pela frustração com as instituições democráticas. Em contraste a noção de que participação política acentuada em extremos alcançando amplos setores da sociedade pode gerar uma sobrecarga de demandas impossíveis de serem atendidas, abalando as estruturas democráticas. Não é, portanto, um elemento vital para a sobrevivência da democracia, a participação política. Outros diferentes modos de engajamento político podem ser determinados.

$\mathrm{O}$ apoio ao regime pode resultar em diferentes formas de participação que podem ser relacionadas aos modelos convencionais e também as formas envolvendo os protestos políticos que podem trazer rupturas e instabilidades ao regime democrático, confrontando o sistema. Cidadãos com baixos níveis de apoio institucional são os mais propensos a protestar e contribuir para as instabilidades que a desobediência possa contribuir. A insatisfação com o regime permite maior engajamento político através dos mecanismos convencionais de participação e são propensos aos protestos e manifestações. Estas quedas no apoio popular ao sistema político resultam em conflitos e crises que geram as instabilidades políticas na América Latina.

A estabilidade política tem uma relação direta com o êxito das políticas públicas sobretudo na tomada de decisões do governo especialmente relacionado a segurança, economia e liberdades. Para Pikketty os benefícios sobre a democracia quando se refere a transparência financeira e taxação sobre fortunas com finalidade de melhor distribuição de renda são essenciais para legitimar o regime:

\footnotetext{
A transparência financeira associada ao imposto global (como uma proposta do autor - grifo nosso) iria gerar preciosas informações sobre a distribuição de riqueza. Os governos nacionais, as organizações internacionais, e os institutos de estatística ao redor do mundo iriam pelo menos ser capazes de produzir dados confiáveis sobre a evolução da riqueza global (...). Os cidadãos teriam acesso a dados públicos sobre fortunas, cujas informações seriam fornecidas por lei. (PIKKETTY, 2013, p. 518-519)
}

Aspectos relativos ao movimento de retomada democrática e resgate ao crédito das instituições, é considerado várias dimensões inseridas no discurso populista trazendo todos valores que urge nas aspirações populares a exemplo da igualdade política, equilíbrio econômico, soberania popular, justiça social, 
nacionalismo, anti-imperialismo, antioligarquismo, modernização e reformismo. As lideranças populistas então firmam o compromisso no discurso e em cima da retórica impetuosa e farta de excessos estabelece uma conexão de crédito e esperança com as massas.

No campo econômico a ênfase dos programas focam na redistribuição da riqueza e usam de pretensões de amparo coletivo por parte do Estado para garantir o acesso ao poder e agir as margens da lei para justificar tal ato nobre em favor dos carentes. É evidente que o líder populista, em defesa de causa própria, usufrui da demagogia para conciliar o discurso ao ressentimento das massas contra as elites e contra o imperialismo das grandes potencias, afim de montar uma estrutura materializada do inimigo que precisa ser aniquilado. Um dos elementos que favoreceram a emergência de movimentos populistas nestas nações foram as precárias condições estruturais, de ordem econômico-social. Os líderes populistas capitalizam, habilmente, as crises econômicas, desenvolvendo um discurso político que "sensibiliza" as massas.

Para Greenspan o populismo no campo econômico segue uma cartilha simplista e objetiva, pelo menos no discurso. Para os defensores do populismo as grandes estruturas teóricas são construções montadas para dispersar as reais necessidades da vida prática.

\footnotetext{
"Se há desemprego, o governo deve contratar os desempregados. Se o dinheiro está escasso e as taxas de juros estão altas, o governo deve impor limites artificiais imprimindo mais dinheiro. Se as importações estão ameaçando empregos, proíbe-se as importações." (GREENSPAN, 2008, p. 326).
}

No âmbito político, anula-se qualquer oposição que venha confrontar embates de ideias e assim oxigenar uma democracia pluralista para dar relevo as pretensões autoritárias assumidas pelo líder. O papel do líder neopopulista na dominação das massas é proporcionada pela mídia e pelas pesquisas de opinião agregadas ao amparo assistencialista, desta forma consegue atrair os eleitores que aderem em massa a sua campanha política. Neste panorama o paternalismo da relação convive plenamente com antigas formas de patrimonialismo como mecanismo de dominação. O discurso demagogo imposto fortemente por uma mídia tendenciosa e construída para conceber uma ideologia populista, transforma a já fragilizada democracia em alicerce para o autoritarismo. O reforço midiático e da imprensa parcial voltada para os interesses do líder populista engendra toda espécie de artifícios 
para manejar a opinião.

No entanto as frustrações do funcionamento prático deste tipo de regime marcado pelo nacionalismo, centralização de poder e fragilização das instituições democráticas, geram uma erosão de apoio as camadas mais influentes da sociedade e deteriora difusamente a democracia.

A débil condição econômica contribui para que as tomadas de decisão das massas sejam motivadas por interesses pessoais, daí se tornarem tão vulneráveis a manipulação populista e operarem por meio de redes clientelísticas no qual o eleitor troca apoio eleitoral por favores para obtenção de serviços essenciais. Daí a necessidade de manutenção precária dos serviços e Estado inoperante, afim de manter a população cada vez mais dependente do governo, que privados destes bens e serviços se tornam massas de manipulação.

A necessidade de uma reformulação da democracia afim de ampliar a participação irá oxigenar o regime na América Latina. Diante da desesperança os próprios apoiantes se habituaram as limitações restritivas da liberdade que caracteriza o regime até tolerando violações aos direitos humanos e anuindo com indiferença o destino dos interesses que se alinham as pretensões de uma elite ambiciosa.

O compromisso desta nova leitura a ser feita à busca de uma democracia conectada com a sociedade é ampliar as dimensões da qualidade da democracia com o exercício livre do direito que venha contribuir para facilitar o acesso ao processo político e as suas instituições. Levine e Molina (2007, p. 24) ressalta que estes direitos devem convergir para que a decisão eleitoral, igualdade de acesso e tratamento das instituições políticas e responsabilidade políticas estejam conformadas aos processos democráticos restaurados por uma participação política sob o arrimo de um sistema judicial célere e eficiente, com mecanismos de transparência e de direitos que garantam a liberdade de organização e direito a informação.

\section{AMÉRICA LATINA: UMA CULTURA DE TRANSGRESSÕES}

Constata-se que os sistemas de representação permanecem sem corresponder à vontade/necessidades dos cidadãos e em muitas vezes têm reduzido as oportunidades de opinião e acesso dos cidadãos; os pobres estão mais dependentes do que nunca do Estado e completamente vulneráveis aos carismáticos líderes populistas; os apáticos grupos de classe média a esperar nas instáveis alianças eleitorais (sem quaisquer 
credibilidade) e ou na força persuasiva dos meios de comunicação alguma modificação significativa na dinâmica política e econômica de seus Estados.

Palco de inúmeros episódios que corroem a confiança dos indivíduos nas instituições do Estado, a América Latina estampa uma realidade dramática à coesão social: violência urbana armada e surgimento de crimes organizados abrigados em redes internacionais; fenômenos de corrupção entre os políticos, altos funcionários e a polícia, agregados à ineficiência do sistema Judiciário.

Signo maior da impotência do Estado e da expansão da cultura da transgressão e do crime, a violência urbana armada é interpretada como um meio de obter pela força o que não é possível conseguir por vias formais. Entende-se a desigualdade social e a consequente dissonância entre as expectativas do indivíduo e sua incapacidade de satisfazê-las por meios legais como fatores desencadeantes ao grave problema da violência, especialmente a partir dos anos 2000, assim observa Sorj e Martuccelli (2008).

A gravidade do problema gerado pela violência não se restringe à segurança pública, estendendo-se, portanto, aos aspectos econômicos e sociais. A violência contribui para um maior dispêndio nos serviços de saúde (mais internações hospitalares e consumo de remédios) além de comprometer a subsistência de muitas famílias que têm seus entes provedores machucados e ou assassinados cotidianamente. No aspecto social, intenso é o impacto da violência no ensejo de insegurança e medo a conspirarem contra a solidariedade entre os indivíduos e alimentarem uma dinâmica sócio-destrutiva: enquanto a classe média passa a estigmatizar como delinquentes os mais pobres, estes utilizam-se da violência e incivilidade para proteger-se da exclusão a que são submetidos.

Vislumbra-se como grupo de risco ao envolvimento com a violência os homens jovens (15 a 29 anos) provenientes de setores de baixa renda; nascidos em famílias instáveis, fragilizadas pela ausência da figura paterna que não chegam a ser analfabetos mas tampouco capacitados para progredir no mercado econômico contemporâneo e portanto exploram atividades no mercado informal, que, por sua vez, propicia atividades criminosas como o tráfico de drogas, mercado ilegal de armas e etc.

O crescimento do tráfico de drogas significou, em muitos países o fortalecimento dos grupos sofisticadamente armados que, aproveitando-se do despreparo dos Estados, passaram a locupletar-se com o quadro desestabilizador de 
desafeição dos cidadãos para com o Estado e a controlar consideráveis espaços urbanos e rurais. Nesse contexto, se destacam o Brasil, Colômbia e México cuja atividade de tráfico de drogas tem grande impacto político e social, estando infiltrada nas mais diversas estruturas do Estado.

A trama de transgressões em que estão envolvidos os países Latino Americanos em muito se deve ao crime organizado patrimonialista manifestado sob a forma de corrupção pública, onde poderosos empregam junto às instituições do Estado uma dinâmica inescrupulosa em favor e em satisfação de seus interesses particulares. Se em outra época era considerada parte dos privilégios e das "regras do jogo" dos grupos de poder, protegida pela distância social, hoje ela é cada vez mais considerada pela população um feito delituoso, ensejador de revolta social. Forte é o consenso, entre os economistas, que a corrupção tem um impacto negativo sobre a economia dos países na medida em que reduz a transparência dos mercados, impede a competição saudável dos preços e a qualidade dos produtos e serviços.

A corrupção é um fenômeno universal, sendo diferenciados, no entanto, o nível de impunidade desta entre os Estados. Em comparação aos países europeus e Estados Unidos da América, alto é o índice de corrupção e impunidade na América Latina desde muito refém de regimes de governos autoritários e populistas que, diante do uso arbitrário do poder e impondo limitações à expressão da opinião pública e à autonomia do Judiciário, mitigam a capacidade democrática da população e, por sua vez, a capacidade de punição dessa forma de crime organizado de alto escalão.

A asseverar ainda mais o panorama de transgressões a que estão imergidos nos países latino-americanos vislumbra-se a corrente insatisfação da população com o desempenho do Judiciário. A justiça tem sido percebida como pouco confiável, lenta, custosa, desigual entre ricos e pobres. Nesse sentido são as alegações de Sorj e Martuccelli:

\footnotetext{
A representação histórica que se possui da relação com as normas nos países latino-americanos agrava o sentimento de enfraquecimento ante a expansão de fenômenos delituosos ou criminais. O resultado, do ponto de vista da experiência entre os indivíduos, é menos o sofrimento de viver em uma sociedade verdadeiramente anômica (sem regras - como enunciou Durkhein no final do século XIX) do que o sentimento de estar condenado a atuar em sociedades em que a norma tem caráter bifronte, pois seu uso difere em função da pessoa com quem entra em ralação (no dito da tradicional política brasileira: 'aos amigos se faz justiça, aos inimigos se aplica a lei’). (SORJ; MARTUCCELI, 2008, p. 157)
} 
Esta percepção de um Judiciário injusto é uma das manifestações mais dramáticas e perigosas à coesão social, haja vista ensejar sentimentos mesclados de indignação, cinismo e apatia.

A impunidade, até mais que a corrupção, provoca a desmoralização das instituições estatais, a revolta e indignação dos cidadãos e, por consequente, afeta a coesão social. Para a consolidação de um ideal democrático aberto e igualitário há de se não mais tolerar qualquer tipo de transgressão, impunidade e ineficácia judicial.

\section{A COESÃO SOCIAL NA LEGITIMAÇÃO DA DEMOCRACIA}

A democracia vem a ser a emancipação dos indivíduos cidadãos para que participem ativamente nas decisões políticas, econômicas e sociais do Estado e livremente façam suas escolhas de estilo de vida, consumo, lazer sem quaisquer pressões intervencionistas privadas e ou públicas. Já a cidadania, em crescente expansão desde a instauração do Estado constitucional, inicialmente, ante ao Estado Liberal, assumiu a postura passiva, voltada fundamentalmente para a proteção da vida, liberdade e propriedade na esfera da vida privada e familiar, entendendo a política como algo alheio, de responsabilidade tão somente dos políticos profissionais. Diante do Estado Democrático, a cidadania consolida-se como ativa e participativa em que o cidadão, através do sufrágio universal (representativo ou direto), atua na vida política da comunidade. Finalmente, conforme assevera Nabais (2007), frente à construção, ainda nebulosa e indefinida, do Estado Solidário vislumbra-se a cidadania solidária, onde o cidadão consciente de seu protagonismo na vida pública assume conjuntamente aos poderes públicos constituídos a responsabilidade pela dinâmica do Estado. Tal cidadania solidária vem a acrescer, e não substituir, à cidadania passiva do Estado Liberal e ativa do Estado Democrático.

A cidadania solidária, fundamentada no pressuposto marxista de que os homens fazem história, segundo a determinadas circunstâncias estruturais, intenta uma revolução interna nos cidadãos para que, destituindo-se da situação de meros receptores de proteção social, percebam e assimilem o seu espaço de protagonistas no mundo, sujeitos de direitos e deveres, vindo a promover forças para modificar a desordem mundial e, por conseguinte, o seu destino e o destino das gerações futuras. Solidariedade essa no sentido de co-responsabilidade de cada um dos indivíduos na 
assunção da gerencia de suas vidas, escolhas, hábitos e comportamentos institivamente arraigados às tradições sem permitir a interferência despreocupada de forças econômicas comprometidas única e exclusivamente, em detrimento da cidadania e identidades, com seus lucros. Solidariedade então capaz de ressocializar os direitos sociais centrados no indivíduo em direitos sociais centrados na comunidade o que possibilitaria pois a instituição de um sistema de bem estar universal.

Nesse sentido são seguintes alusões de Cerquier - Manzini:

a revolução por uma sociedade melhor passa pela revolução nas
subjetividades das pessoas. Um dos níveis dessa revolução está na
possibilidade de o homem contemporâneo romper cotidianamente com as
trevas da alienação (e uma delas seria o consumismo exagerado,
compulsivo. (Cerquier - Manzini, 2010, p. 87)

Partindo da premissa de que o mal estar social, provocado pelas desigualdades sociais, pobreza crônica e dificuldade para sobreviver, trata-se de obstáculo à cidadania haja vista bloquear a capacidade de criação de instituições para o desenvolvimento da sociedade civil, urge a afirmação de uma cultura democrática e para tanto Cerquier - Manzini (2010), ressalta o resguardo do traço básico da cidadania, qual seja, o fato de as pessoas exteriorizarem, por meio da ação social, a crítica construtiva do comum e nesse sentido reverter o direcionamento tecnológico à satisfação do bem estar da população.

As novas tecnologias fortemente implantadas e utilizadas nos Estados contemporâneos pós modernos têm, em muito facilitado a interação social e desde que respeitem a complexa ideia de segurança e individualidade são consideradas valiosos instrumentos a favor da liberdade responsável e democracia.

Merece menção a revolução qualitativa nas relações humanas desencadeadas pela internet e redes sociais. Estas, do ponto de vista ético, são neutras e plausível seu uso voltado a aproximar pessoas, patrocinar campanhas humanitárias, disponibilizar informações, ativar discussões coletivas sobre políticas públicas e ouvir a sociedade, legítima detentora do poder, numa nítida afirmação da cidadania e democracia e numa salutar possibilidade de compartilhamento de responsabilidades pela tomada de decisões políticas entre os atores sociais como o setor privado, a sociedade civil e o governo, no sentido de uma definitiva superação da ideia paternalista de que cabe tão somente ao governo resolver tudo. 
Imperioso à democracia a afirmação de uma sociedade civil atuando com liberdade responsável e consciente de sua capacidade. Extremamente contextualizadas as palavras de Thomas Jefferson, extraídas da obra Jihad x McMundo - Como o globalismo e o tribalismo estão transformando o mundo:

\begin{abstract}
Quando cada homem for participante da condução desta república [...] e sentir que é participante da condução das questões nacionais não só em dia de eleições, mas todos os dias; quando não houver um só homem no país que não seja membro de algum conselho, pequeno ou grande, será mais fácil arrancar o coração de dentro de seu peito do que retirar dele o poder. (BARBER, 2003, p. 326)
\end{abstract}

Reconhecer a imprescindibilidade da efetivação de uma sociedade civil pro ativa no contexto de mundo contemporâneo já é o primeiro passo ao ideal democrático socialmente responsável.

\title{
CONSIDERAÇÕES FINAIS
}

A qualidade dos sistemas de representação política nos países latinoamericanos merece apreciação crítica quanto à liberdade e igualdade políticas, oportunidades de opinião e acesso aos cidadãos à coisa pública. Desarraigados da manipulação dos carismáticos e influenciadores líderes populistas, imprescindível a adesão popular no enfrentamento das várias questões sociais, políticas e econômicas em uma espécie de cidadania inclusiva e co-responsabilização de todos no destino dos Estados latino-americanos que se alegam democráticos.

Além do sufrágio universal, eleições e mandados periódicos, a concretude da democracia depende do maior grau de informação e educação do eleitorado a conscientemente direcionarem suas escolhas representativas àqueles verdadeiramente compromissados com os interesses e necessidades sociais. Ademais, a inteiração social mobilizada e fiscalizadora do funcionamento da máquina administrativa unicamente em prol dos interesses públicos funciona, juntamente com as leis e normas administrativas e o sistema de freios e contrapesos exercidos pelos Poderes Executivo, Legislativo e Judiciário, como um mecanismo de responsabilização social em prol da probidade pública.

Propõe-se, portanto, a coesão social como mecanismo plausível para a consolidação do ideal democrático. A maior participação popular na coisa pública influenciando as decisões políticas se coloca como uma metodologia de atuação e de descentralização do Estado nas decisões que importam a todos os atores sociais no 
exercício legitimado de suas cidadanias e consequente consolidação do ideal democrático. Quanto menos autônomo e centralizado for um governo maior será a qualidade e legitimidade de sua democracia.

\section{REFERÊNCIAS}

AVRITZER, Leonardo (2002) “Teoria democrática e deliberação pública". Lua Nova, no. 49, p. 25-46.

BARBER, Benjamin R., 1939. Jihad x McMundo - Como o globalismo e o tribalismo estão transformando o mundo. Tradução de Gabriela Máximo. Rio de Janeiro. Editora Record, 2003.

BOOTH, John A., and MITCHELL A. Seligson. The Legitimacy Puzzle in Latin America: Political Support and Democracy in Eight Latin American Nations. Cambridge: Cambridge University Press. 2009.

CERQUIER-MANZINI, Maria Lourdes. O que é cidadania. 4 ed. São Paulo. Ed. Brasiliense - Coleção Primeiros Passos. 2010.

DAHL, Robert A On Democracy. New Haven: Yale University Press, 1998 Apud LEVINE, Daniel H e MOLINA, José Enrique. La Calidad de La Democracia en América Latina: Una Visión Comparada. Salamanca. América Latina Hoy, num 45, 2007. p. 17-46.

DUSSEL, Enrique. 20 teses de política. São Paulo: Expressão Popular, 2007. 184 p.

EMÉNDZ, Ana e MORALES, Elda "O populismo na América Latina." Problemas em Policy Review. Instituto de Estudos Políticos e Direito Público da Faculdade de Direito e Ciência Política. LUZ. No. 34, 2005.

GUERREIRO, Mário; OLIVA, Alberto. "Populismo: ilusionismo e auto-engano". In: Banco de Ideias. Rio de Janeiro, vol. 10, no. 37 (dezembro 2006, janeiro/fevereiro 2007). p. 7-10.

GREENSPAN, Alan. "América Latina e populismo". In: A era da turbulência Aventuras em um novo mundo. (Apresentação de Pedro Malan; tradução de Afonso Celso da Cunha Serra). Rio de Janeiro: Elsevier, 2008. p. 322-332.

LEVINE, Daniel H e MOLINA, José Enrique. La Calidad de La Democracia en América Latina: Una Visión Comparada. Salamanca. América Latina Hoy, num 45, 2007. p. 17-46.

MAINWARING, Scott. Introduction: Democratic Accountability in Latin America. En MAINWARING, Scott y WELNA, Christopher (eds.). Democratic Accountability in Latin America. Oxford: Oxford University Press, 2003. p. 3-33. 
MAINWARING, Scott, BEJARANO Ana Maria, and LEONGÓMEZ, Eduardo Pizarro. The Crisis of Democratic Representation in the Andes. Palo Alto, CA: Stanford University Press. 2006.

ORON, Atilio A. Aristóteles em Macondo: Notas Sobre el Fetichismo Democrático em América Latina. Córdoba: Espartaco Córdoba, 2009. 84 p.

PIKKETY, Thomas. O capital no século XXI. Tradução de Mônica Baumgartem de Bolle. Rio de Janeiro. Ed. Intrinseca. 2013. p. 518-519.

RENNÓ, Lucio R.; SMITH, Amy E.; LLOYD, Mattheu L.; PEREIRA, Frederico Pereira. Legitimidade e qualidade da democracia no Brasil: uma visão da cidadania. São Paulo: Intermeios; Nashville: LAPOP, 2011.

ROMERO, Hannibal. A miséria do populismo Mitos e Realidades da democracia na Venezuela. Panapo Editorial, terceira edição. Caracas. 1996.

MARTUCELLI, Danilo e SORJ, Bernardo. O desafio latino-americano: coesão social e democracia. - Rio de Janeiro: Civilização Brasileira, 2008.

NABAIS, José Casalta. Por uma Liberdade com Responsabilidade: Estudos sobre Direitos e Deveres Fundamentais. Coimbra Editora, 2007.

TAGUIEFF, Pierre-André. L'Illusion populiste - Essai sur les démagogies de l'âge démocratique. 2 ${ }^{\mathrm{a}}$. Edição. Paris: Flammarion, 2007.

VÉLEZ-RODRÍGUEZ, Ricardo. Patrimonialismo e a realidade latino-americana. Rio de Janeiro: Documenta Histórica, 2006.

VILAS C.M., Democracia e Neoliberalismo: os líderes da eleição da pósmodernidade. Socialismo e Participação . n. 69, 1995. p. 31-43. 